\title{
RELATOS DE PESQUISA
REDUÇÃO DE FUNGOS EM AMBIENTE DE BIBLIOTECA:
VIABILIDADE DE APLICAÇÃO DE NEBLINA ATIVADA
}

\author{
Ana Lúcia Pereira de Carvalho Ribeiro \\ Mestre em Ambiente, Saúde e Trabalho pela Universidade Federal da \\ Bahia, Brasil. \\ E-mail: alpcribeiro@hotmail.com \\ Nídia Maria Lienert Lubisco \\ Doutora em Documentação pela Universidad Carlos III, Espanha. \\ Professora da Universidade Federal da Bahia, Brasil. \\ E-mail: nidialubisco@gmail.com
}

\begin{abstract}
Resumo
A qualidade do ar em ambientes de trabalho tem influência direta na qualidade de vida e bem-estar das pessoas que ocupam ou transitam nesses locais. Contaminantes biológicos, como fungos e bactérias, utilizam o material particulado (pólen, escamas de pele humana, pelos, poeira entre outros) como substrato para se multiplicar. Estudos revelam que em ambientes fechados, com ventilação e climatização artificiais, é comum os ocupantes apresentarem sintomas persistentes, tais como: alergia, dor de cabeça, irritação nos olhos e nas mucosas, dores de garganta, tonturas e fadiga. As bibliotecas constituem um desses ambientes e, no caso brasileiro, apesar das normas existentes, há poucos estudos a respeito e praticamente nenhuma iniciativa de qualificação do ar dessas unidades. Algumas tecnologias como filtração do ar, irradiação ultravioleta e outras já foram e continuam sendo desenvolvidas para reduzir a concentração de bioaerossois nesses ambientes. Este trabalho tem como objetivo analisar a efetividade do sistema de neblina quimicamente ativada para a redução de fungos no ambiente interno de bibliotecas. As medidas quantitativas de fungos no ar foram realizadas no interior na Bibliotheca Gonçalo Moniz, a unidade histórica da Faculdade de Medicina da Bahia, localizada no Centro Histórico de Salvador, com e sem o uso do sistema de neblina quimicamente ativada. O uso do sistema atingiu a redução de até $95 \%$ dos fungos presentes no ar interior da biblioteca. Originada do campo da saúde do trabalhador, esta pesquisa e seus resultados, por sua relevância, podem suscitar novos estudos, bem como determinar políticas institucionais de largo alcance para ambientes de bibliotecas, no país.
\end{abstract}

Palavras-chave: Qualidade do ar. Ambientes internos. Bibliotecas. Fungos. Bioaerossois.

\section{REDUCTION OF INDOOR FUNGI ON THE INSIDE OF THE LIBRARY: ACTIVATED FOG APPLICATION VIABILITY}

\begin{abstract}
The quality of the air breathed in work environments has a direct influence on the quality of life and well being of persons occupying or transiting in this environment. Biological contaminants such as fungi and bacteria use the particulate matter (pollen, flakes of human skin, hair, dust and others) as a substrate to multiply. Studies revealed that indoors with artificial ventilation and air conditioning, the occupants had in general persistent symptoms of varying severity, such as allergies, headaches, eye mucosa irritation, sore throat, dizziness and fatigue. Libraries are one of these environments and, in Brazil, despite the existing rules, there are few studies and virtually no initiative of qualification on the air in these units. Some technologies such as air filtration, ultraviolet irradiation, and others have already been and are being developed to reduce the concentration of bioaerosols in indoor environments. This work aims to analyze the effectiveness of the chemically activated fog system for the reduction of indoor fungi on the inside of the library. Quantitative measurements of fungi in air were carried out within the Bibliotheca
\end{abstract}

Perspectivas em Gestão \& Conhecimento, João Pessoa, v. 6, n. 2, p. 36-52, jul./dez. 2016. http://periodicos.ufpb.br/ojs2/index.php/pgc. ISSN: 2236-417X. Publicação sob Licença (cc) EY-Nc-ND 
Gonçalo Moniz, the former library of the School of Medicine of Bahia, located in Largo do Terreiro de Jesus, Historical Center, Salvador, Bahia, with and without the use of chemically activated fog system. The use of the system managed to reduce up to 95\% of the fungus in the air on the inside of the library. Originated from the occupational health field, this research and its results, their relevance, may raise new studies and determine broad range institutional policies for library environments in the country.

Keywords: Quality air. Indoor environment. Libraries. Contaminantes. Fungi. Bioaerosols.

\title{
1 INTRODUÇÃO
}

Os ambientes com ventilação inadequada ou sem ventilação são propícios ao desenvolvimento de micro-organismos, podendo afetar a saúde das pessoas que neles circulam ou permanecem por força da jornada de trabalho. Ar interior é a denominação do ar respirado em ambientes fechados, tais como, escolas, hospitais, bibliotecas, cinemas, shopping centers, escritórios, prédios, meios de transporte, entre outros.

As bibliotecas brasileiras, pelas características do material que abrigam prioritariamente, impressos - constituem o alvo perfeito para insetos e micro-organismos, como fungos e bactérias. Apesar de tratar-se de um tema inserido na área de saúde ocupacional, ele não figura com proeminência na literatura. No entanto, os poucos estudos de que se tem conhecimento já seriam suficientes para provocar a elaboração de políticas e legislação específica, considerando os malefícios que um ambiente interior infestado ou contaminado pode acarretar ao ser humano.

Ante o exposto, desenvolveu-se este estudo com o objetivo de analisar a efetividade do uso do sistema de neblina quimicamente ativada na redução de fungos em biblioteca e determinar o percentual de redução de fungos na biblioteca avaliada. Para cumprir tal objetivo, o presente artigo se apresenta em seis partes, além desta seção introdutória, a saber: Biblioeca universitária: funções e desafios; Qualidade do ar de ambientes interiores; Material e método; Resultados; Discussão; e Conclusão.

\section{BIBLIOTECA UNIVERSITÁRIA: FUNÇÕES E DESAFIOS}

A biblioteca universitária, na perspectiva de alinhar-se às demandas informativas da sua comunidade e aos recursos técnicos e tecnológicos disponíveis na contemporaneidade para o desempenho de suas funções acadêmico-pedagógicas, deve pautar-se em princípios e métodos do planejamento estratégico e da gestão de qualidade. Nessa mesma perspectiva, o cumprimento da missão social das universidades, conceitualmente, está diretamente vinculado, por parte das bibliotecas universitárias, ao cumprimento de suas funções tanto clássicas quanto inovadoras:

\begin{abstract}
As bibliotecas universitárias [...], por sua natureza, desempenham um papel fundante na instituição à qual estão ligadas, por sua função de apoio ao desenvolvimento dos programas de ensino, pesquisa, extensão e inovação. Essa função se consubstancia na sua atuação como recurso didáticopedagógico (laboratório de aprendizagem); como plataforma de conhecimento (considerando-a fonte e local de registro da produção técnica e científica da instituição); e como fator de estímulo à formação e ao desenvolvimento do espírito científico. (LUBISCO, 2015, p. 5)
\end{abstract}

De forma inerente, seu ambiente físico deve atender aos requisitos ditados pelas normas da funcionalidade, do conforto ambiental e da ergonomia e por aqueles referentes à

Perspectivas em Gestão \& Conhecimento, João Pessoa, v. 6, n. 2, p. 36-52, jul./dez. 2016. 
qualidade do ar interior, seja para o bem-estar do pessoal que ali trabalha e transita, seja para a conservação dos materiais bibliográficos e informacionais sob sua guarda.

No Brasil, apesar dos trabalhos existentes sobre prevenção e conservação para ambientes de biblioteca e de arquivo, ainda é corriqueiro encontrar-se ambientes que, pela simples observação, demonstram sua inadequação a pessoas e a materiais informativos, em qualquer tipo de mídia. Tanto é assim que padrões oficiais para controle de temperatura e de umidade em geral não soem ser adotados como norma. Norma Cianflone Cassares, em seu livro Como fazer conservação preventiva em arquivos e bibliotecas (2000, p. 15), apresenta as seguintes orientações a respeito: "o mais recomendado é manter a temperatura o mais próximo possível de $20^{\circ} \mathrm{C}$ ( 18 a $22^{\circ}$ ) e a umidade relativa de $45 \%$ a $50 \%$, evitando-se de todas as formas as oscilações de $3^{\circ} \mathrm{C}$ de temperatura e $10 \%$ de umidade relativa" (grifo nosso).

Seguramente, umidade e temperatura, ao lado de higienização regular, são variáveis que interferem na qualidade do ar que se respira dentro de bibliotecas e arquivos; por sua repercussão na saúde dos sujeitos e dos objetos dessas unidades de informação, o controle dessas variáveis passa a integrar o rol de desafios a que elas estão sujeitas. ${ }^{1}$

\section{QUALIDADE DO AR DE AMBIENTES INTERIORES}

A qualidade do ar de interiores, assim, é um assunto relevante e nos últimos anos tornou-se importante tema de pesquisas na área de saúde pública. (AGÊNCIA NACIONAL DE VIGILÂNCIA SANITÁRIA, 2003, WANG; ANG; TADE, 2007; QUADRO, 2008) Essa relevância devese principalmente à perda de produtividade e aos índices de absenteísmo no ambiente de trabalho, devido a sintomas como fadiga, dor de cabeça, tontura, náusea, apatia, sonolência, cansaço, fraqueza, dificuldade de concentração, urticária, irritação e secura na pele, falta de ar, chiado no peito, coriza, irritação no nariz e na garganta, dor de garganta, irritação, ardor e lacrimejamento nos olhos, rinite alérgica, asma brônquica, doença do Legionário, febre de Pontiac, histoplasma, entre outros. (BRICKUS; AQUINO NETO, 1999; GIODA; AQUINO NETO, 2003; GIODA, 2003) Em consequência da má qualidade de ar interior, surgiu a Síndrome do Edifício Doente (SED) e a Doença Relacionada ao Edifício (DRE). (WANG; ANG; TADE, 2007; GIODA; AQUINO NETO, 2003)

Em 16 de janeiro de 2003, a Agência Nacional de Vigilância Sanitária (ANVISA) aprovou resolução estabelecendo padrões referenciais de qualidade do ar interior em ambientes artificialmente climatizados, de uso público e coletivo. Foi estabelecido o Valor Máximo recomendável (VMR) de 750 ufc.cm-3 para fungos, para a relação $\mathrm{I} / \mathrm{E} 1,5$, onde I é a quantidade de fungos no ambiente interior e $E$ é a quantidade de fungos no ambiente exterior. Em nota dessa resolução, esclareceu a ANVISA que a relação I/E é exigida como forma de avaliação frente ao conceito de normalidade, representado pelo meio-ambiente exterior e a tendência epidemiológica de amplificação dos poluentes nos ambientes fechados. A ANVISA estabeleceu também que, quando o VMR for ultrapassado ou a relação $\mathrm{I} / \mathrm{E}$ for $>1,5$, é necessário fazer um diagnóstico de fontes poluentes para uma intervenção corretiva.

A poluição do ar interior é considerada um dos principais problemas ambientais e de saúde pública. Estima-se que cerca de metade da população mundial, ou seja, mais de 3 bilhões de pessoas, sofre com a qualidade do ar de interiores, principalmente as pessoas nos países subdesenvolvidos e em desenvolvimento. (BRUCE, 2000) Ito e Aguiar (2007) pesquisaram material particulado e alguns gases poluentes (amônia, cloro, dióxido de carbono, ozônio, benzeno, monóxido de carbono e tolueno) presentes em ambientes internos de bibliotecas públicas localizadas em São Paulo e São Carlos. Os resultados mostraram que as concentrações de particulados apresentaram valores sempre maiores nos ambientes internos

\footnotetext{
${ }^{1}$ Sobre padrões de qualidade para biblioteca universitária, ver Lubisco (2015).
} 
das bibliotecas do que nos externos e, para os gases avaliados, apenas o dióxido de carbono foi constatado no interior das bibliotecas, com valores dentro dos padrões referenciais da qualidade do ar interior.

Há evidências obtidas em estudos epidemiológicos de uma associação de fungos com o aumento das taxas de doenças do trato respiratório superior. Os efeitos sobre a saúde, causados pelos fungos que podem ser encontrados no ar exterior e interior, não são os mesmos e há uma grande variação de sensibilidade individual. Com base na evidência atual, ainda não é possível recomendar um nível aceitável e seguro de qualquer tipo de esporos do fungo que ocorre no ambiente interior. (NATIONAL INSTITUTE FOR OCCUPATIONAL SAFETY AND HEALTH, 2009)

Uma avaliação da qualidade do ar interno realizado na Biblioteca Central da Universidade do Vale da Paraíba (UNIVAP) revelou a presença de diferentes fungos de importância médica, entre eles os predominantes Phaeoacremonium, Parasiticum $e$ Acremonium sp., causadores de doenças dermatológicas, e Penicillium sp., causador de doenças respiratórias. Por meio da aplicação de questionários aos ocupantes e funcionários, foram identificados altos índices de queixas dermatológicas (73\%), irritação nasal (95\%) e de queixas respiratórias (63\%). Os resultados foram decisivos para o diagnóstico da Síndrome do Edifício Doente na Biblioteca Central da referida Universidade. (PEREIRA et al., 2010)

A fim de minimizar o risco de exposição, muitas tecnologias foram desenvolvidas para reduzir a concentração de bioaerossois em ambientes interiores, tais como filtração do ar, irradiação ultravioleta, diferença de pressão entre recintos, precipitação eletroestática, ionização negativa do ar, adsorção de carbono, ozonização do ar, oxidação fotocatalítica, entre outras, mas nenhuma inteiramente satisfatória. (INDOOR ENVIRONMENT CENTER, 2013)

Por essa razão, decidiu-se verificar a efetividade do uso do sistema de neblina quimicamente ativada na redução de fungos em bibliotecas. O sistema de neblina utilizado para abatimento de fungos do ar foi desenvolvido no Centro de Pesquisas Ambientais da Universidade de Frankfurt - Alemanha (ZUF), baseado na produção dessa neblina, onde as gotículas variam de 10-50 $\mu \mathrm{m}$ de diâmetro, com a finalidade de reduzir mau cheiro de pocilgas. Coube ao Laboratório de Química Analítica Ambiental (LAQUAM), do Instituto de Química da Universidade Federal da Bahia, modificá-lo, aplicando a bioaerossois. (ALVES, 2009; HERNANDEZ, 2011; TAVARES; ALVES; ARCINIEGAS, 2014)

A biblioteca selecionada para estudo foi a Bibliotheca Gonçalo Moniz, antiga biblioteca da Faculdade de Medicina - hoje biblioteca histórica - primeiro curso superior do país, fundado em Salvador, Bahia, em 1808, por D. João VI, quando da vinda da família real para o Brasil. Está localizada no Largo do Terreiro de Jesus, no bairro do Pelourinho, no Centro Histórico da Capital, e integra o Sistema de Bibliotecas da Universidade Federal da Bahia (SIBI/UFBA). Ela se encontra instalada no conjunto arquitetônico da Faculdade de Medicina da Bahia, tendo sido desativada no ano de 1970, quando pequena parte do seu acervo foi transferida para as novas instalações da Faculdade, no campus do Canela, também em Salvador, e a maior parte - de caráter retrospectivo e histórico - continuou nas instalações do Terreiro de Jesus, em condições de preservação não satisfatórias. Em 2003, foi iniciada a recuperação do prédio e os tratamentos técnicos de higienização, restauração, encadernação e tratamento da informação do acervo.

A referida Bibliotheca Gonçalo Moniz ocupa uma área de $5.000 \mathrm{~m}^{2}$. No subsolo, encontram-se a sala de trabalho do bibliotecário, salas de restauração, as torres contendo periódicos em salvaguarda para serem higienizados e recuperados, os laboratórios de higienização e de encadernação, a copa e os sanitários. No térreo, ficam as salas da Coordenação e da Secretaria, os documentos históricos, as obras raras, a coleção da Gazeta Médica da Bahia - primeira revista estritamente científica de Medicina do país -, as salas de pesquisa, de consulta pública; o almoxarifado, as torres de livros e os sanitários, além do salão 
de leitura, do auditório, salas de pesquisa, de reunião e torres de livros, estão localizados no primeiro andar.

Conta com um acervo de 60 mil volumes, entre livros dos séculos XVIII, XIX e XX, periódicos, documentos históricos, obras raras e teses. Está aberta à visitação e à consulta pública. No subsolo, estão armazenados os livros dos séculos XVIII, XIX e XX, como primeira salvaguarda, aguardando processo de higienização e restauração. Grande parte da equipe realiza atividades de higienização, restauração, encadernação e tratamento da informação, com permanente exposição a micro-organismos.

Ante o cenário exposto, o objetivo estabelecido para este estudo foi analisar a efetividade do uso do sistema de neblina quimicamente ativada na redução de fungos em biblioteca e determinar o percentual de redução de fungos na biblioteca avaliada.

\section{Material e método}

Detalham-se aqui as particularidades do local onde foi feita a amostragem, as características do sistema de neblina ativada, o método de amostragem, bem como a forma de cultura e a contagem dos fungos.

\subsection{Local da Amostragem}

As coletas de fungos no ar interior foram feitas no subsolo da Bibliotheca Gonçalo Moniz, onde se encontra o depósito de livros dos séculos XVIII, XIX e XX. As amostragens foram feitas em triplicata no ar interior, antes e depois da passagem pelo sistema de redução de bioaerossois. Para avaliação da relação de fungos no ambiente interno e externo foram feitas coletas do ar na área externa correspondente ao primeiro andar da biblioteca.

\subsection{Sistema de Neblina Ativada}

O sistema de neblina ativada consta de um reator, onde é injetada uma neblina de água contendo uma pequena quantidade de uma mistura surfactante e o ar do recinto contendo bioaerossois. As gotículas de neblina sequestram os micro-organismos e a neblina é desfeita ao fim do reator, sendo o líquido resultante drenado para o esgotamento sanitário e deixando sair o ar purificado.

A neblina é uma suspensão de gotículas no ar. É o sistema mais eficiente de limpeza da atmosfera existente na natureza. A distância entre as gotículas tem $0,5 \mathrm{~mm}$ e a superfície é de aproximadamente $0,5 \mathrm{~m}^{2}$ para $1 \mathrm{~g}$ de água de neblina. Nessa técnica, a produção de neblina ativada é realizada de acordo com o sistema mostrado na Figura 1: o ar é retirado do ambiente por um aspirador, passando por um laminador para organizar o fluxo e é encaminhado para o reator, que consiste em um tubo de PVC de 3 metros de comprimento. Duas bombas de deslocamento positivo tipo pistão, que podem trabalhar com pressões desde 20 bar até 100 bar, levam a solução da mistura surfactante até os aspersores de impacto de alta pressão, capazes de produzir gotículas de neblina de 3 a $4 \mu \mathrm{m}$ de diâmetro, consumindo 0,18 litros de água por minuto. (ALVES, 2009, HERNANDEZ, 2011, TAVARES; ALVES; ARCINIEGAS, 2014) A Figura 2 apresenta a foto do aspersor. $O$ desnebulizador, composto por fibra de aço e de polímeros, atua como obstáculo às gotículas de neblina, fazendo com que essas precipitem e sejam drenadas para o esgoto. 
Figura 1 - Esquema do funcionamento da neblina ativada na captação de fungos no ar

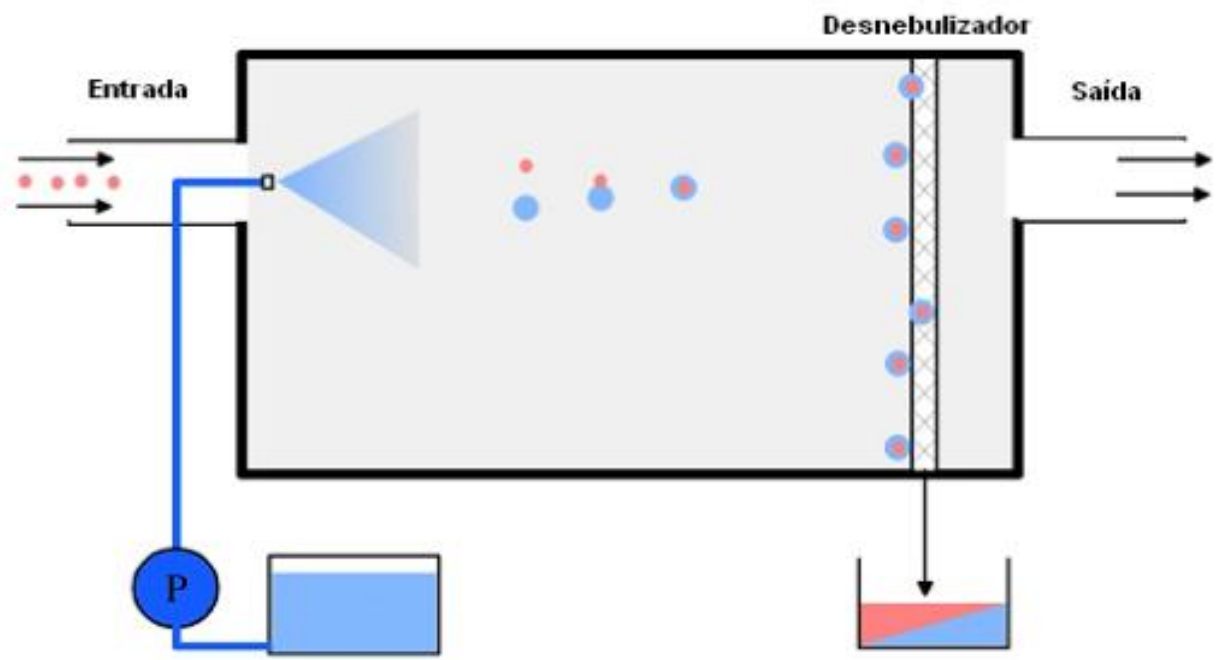

Fonte: Tavares, Alves e Arciniegas (2014), com modificações

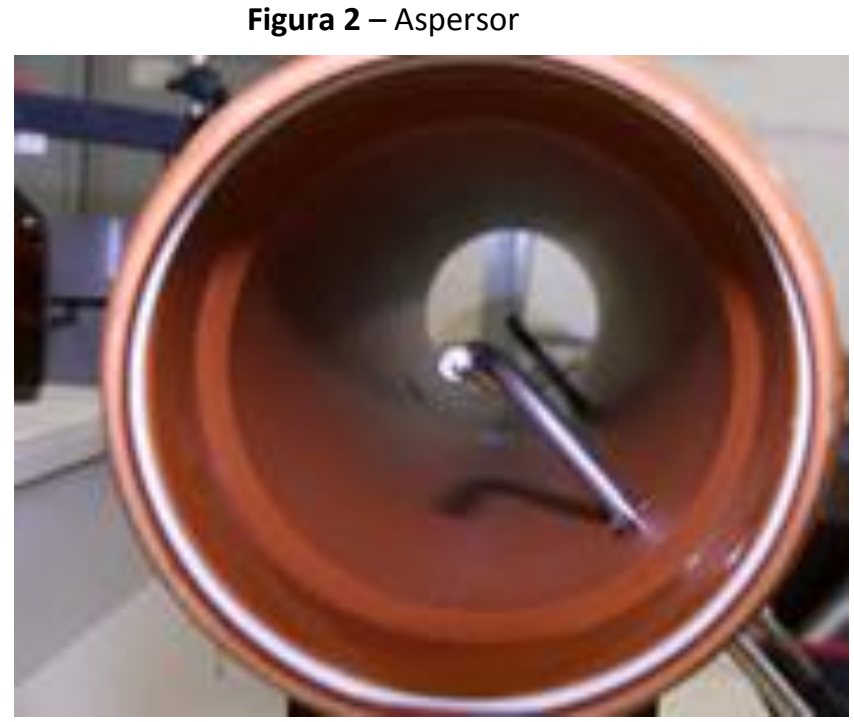

Fonte: Foto tirada durante a pesquisa (RIBEIRO, 2014)

A solução de mistura surfactante utilizada para a redução de micro-organismos é caracterizada por apresentar a natureza anfifílica em suas moléculas, ou seja, apresenta uma parte polar ou hidrofílica e uma apolar ou lipofílica. (BORSATO; GALÃO: MOREIRA, 1999) O surfactante é um composto caracterizado pela capacidade de alterar as propriedades superficiais e interfaciais de um líquido. 


\subsection{Amostragem do Ar}

Há três métodos principais para a coleta de partículas, usados em testes microbiológicos: impactação, filtragem e sedimentação. Os métodos de impactação e filtragem são considerados técnicas de amostragem ativa e exigem a coleta de um volume conhecido de ar. O método de sedimentação é a coleta passiva de contaminação viável no ar em uma placa de petri aberta. (SOCIEDADE BRASILEIRA DE CONTROLE DE CONTAMINAÇÃO, 2007) A escolha do método de amostragem de impactação foi baseada na Resolução RE n. 9, de 2003, da ANVISA, atendendo às características físicas do equipamento de amostragem, tipo e tamanho equivalente a fungos a serem coletados, tempo, duração e local da amostragem.

Para a coleta, utilizou-se um impactador em cascata Andersen de um estágio, coletando-se as partículas de diâmetro aerodinâmico de corte acima de 0,4 $\mu \mathrm{m}$ em placas de petri com meio de cultivo Agar Batata, com ácido tartárico para fungos e bomba de amostragem marca SKC, modelo Quick Take 30, com fluxo constante de ar aspirado de 28,3 L.min-1.

\subsection{Cultura e Quantificação de Fungos}

As amostragens de fungos foram feitas diretamente na placa de petrifilm. O meio de cultura utilizado para determinação de fungos foi o Agar Batata com ácido tartárico, com incubação para formação e crescimento da colônia. A contagem para quantificar as colônias de fungos desenvolvidos foi feita visivelmente por observação direta, utilizando-se lupa e um contador de colônias para ampliar as colônias formadas no meio de cultura. (HUNG et al., 2005).

A efetividade do sistema de neblina ativada para abatimento de fungos foi calculada com base na percentagem referente à quantidade de fungos obtidos após a passagem do ar no sistema com neblina ativada, relacionados com a quantidade determinadas sem a utilização do sistema proposto (ALVES, 2009).

\section{RESULTADOS}

Os fungos no ar no interior e no exterior da Bibliotheca Gonçalo Moniz foram medidos no mês de maio, tendo sido a quantificação baseada no número de unidades de colônias formadas conforme a Resolução 9 de 2003 da ANVISA. Os resultados estão apresentados na Tabela 1. A quantidade de fungos encontrada no ambiente interno foi aproximadamente 0 dobro daquela encontrada no ambiente externo, portanto apresentando uma relação I/E em torno de 1,5. Além disso, o valor mediano do ambiente interno foi de $244,038,3 \mathrm{ufc} / \mathrm{m} 3$, sempre inferior ao VRM estabelecido pela ANVISA de $750 \mathrm{ufc} / \mathrm{m3}$. 
Tabela 1 - Concentrações de fungos $\left(\mathrm{ufcm}^{-3}\right.$ ) no ar interno dentro do depósito de livros da Bibliotheca Gonçalo Moniz, Faculdade de Medicina da Bahia, e fora da Biblioteca, ao ar livre (maio 2014)

\begin{tabular}{lccc}
\hline \multicolumn{1}{c}{ Amostra de ar } & $\begin{array}{c}\text { Mediana } \\
\left(\mathbf{u f c m}^{-3}\right)\end{array}$ & $\begin{array}{c}\text { Desvio médio } \\
\left(\mathbf{u f c m} \mathbf{f r}^{-3}\right)\end{array}$ & $\begin{array}{c}\text { Número de } \\
\text { replicatas } \\
\text { (n) }\end{array}$ \\
\hline $\begin{array}{l}\text { Dentro da biblioteca, } \\
\text { perto da entrada do tubo de } \\
\text { captação de ar (antes) }\end{array}$ & 244,0 & 38,2 & 3 \\
$\begin{array}{l}\text { Fora da Biblioteca ao ar livre, } \\
\text { perto a saída do reator } \\
\text { desligado (depois) }\end{array}$ & 117,0 & 34,7 & 3 \\
\hline
\end{tabular}

Fonte: As autoras

O sistema de neblina ativada foi testado na Bibliotheca Gonçalo Moniz, no mês de maio de 2014, utilizando uma mistura tensoativa com a concentração $1 \%$, para avaliar a efetividade na redução de fungos. Foi analisada a concentração de fungos no ar do interior do depósito de livros da biblioteca e após passagem no sistema de neblina ativada. Os resultados são mostrados na Tabela 2.

Tabela 2 - Concentrações de fungos na avaliação da efetividade do uso da neblina ativada para redução de fungos no depósito de livros da Bibliotheca Gonçalo Moniz (maio 2014)

\begin{tabular}{lccc|c}
\hline \multicolumn{1}{c}{ Amostra de ar } & $\begin{array}{c}\text { Mediana } \\
\left(\mathbf{u f c m}^{-\mathbf{3}}\right)\end{array}$ & $\begin{array}{c}\text { Desvio médio } \\
\left(\mathbf{u f c m}^{-3}\right)\end{array}$ & $\begin{array}{c}\text { Média de redução } \\
\text { (\%) }\end{array}$ & $\begin{array}{c}\text { Número de } \\
\text { replicatas } \\
\text { (n) }\end{array}$ \\
\hline $\begin{array}{l}\text { Dentro da biblioteca, perto da } \\
\text { entrada do tubo de captação } \\
\text { de ar }\end{array}$ & 244,0 & 38,2 & - & 3 \\
$\begin{array}{l}\text { Saída do reator com neblina } \\
\text { ativada, utilizando o }\end{array}$ & 10,6 & 2,3 & 95,7 & 3 \\
tensoativo & & & & \\
\hline
\end{tabular}

Fonte: As autoras

Os resultados da concentração de fungos na biblioteca, antes da passagem do ar pelo sistema, encontraram um valor mediano de 244,0 ufcm- $^{3}$. Após o ar passar pelo sistema de neblina ativada, houve redução da concentração de fungos para 10,6 ufcm- ${ }^{3}$. O uso do sistema de neblina ativada resultou em uma redução em termos de mediana do conjunto das medidas em triplicata de $95,7 \%$.

\subsection{Discussão}

O sistema de neblina quimicamente ativada foi utilizado em trabalhos anteriores, em outras situações, na cidade do Salvador, Bahia. A efetividade na redução de fungos, mediante a aplicação desse sistema, depende, dentre outras variáveis, da composição e concentração da dos tensoativos, faixa de tamanho de gotículas na neblina produzida pelo aspersor, da pressão

Perspectivas em Gestão \& Conhecimento, João Pessoa, v. 6, n. 2, p. 36-52, jul./dez. 2016. 
da bomba e do comprimento do reator. A precisão e a exatidão da quantificação dos bioaerossois dependem da técnica e tempo de amostragem, meio de cultura e leitura das colônias formadas. (ALVES, 2009; HERNANDEZ, 2011; TAVARES; ALVES; ARCINIEGAS, 2014)

O mesmo equipamento usado para geração de neblina neste estudo foi utilizado para estudo semelhante em áreas externas no aterro sanitário de Salvador. Utilizou-se um reator em escala de teste com as mesmas dimensões e com a mesma concentração de uma mistura tensoativa, mas usando o dobro da densidade da neblina ativada. Um abatimento de $93 \%$ dos fungos das emissões da lagoa de chorume do aterro foi alcançado. (ALVES, 2009; TAVARES; ALVES; ARCINIEGAS, 2014) Outro estudo, usando as mesmas condições de abatimento utilizadas no aterro, foi conduzido em dois ambientes interiores do Hospital das Clínicas de UFBA: no ambulatório infantil e no Serviço de Arquivo Médico e Estatística (SAME). Houve uma redução de $91 \%$ de fungos no ar interior, nas duas situações. (HERNANDEZ, 2011)

Nas avaliações realizadas por Hernandez (2011), no Serviço de Arquivo Médico e Estatística (SAME), do Hospital das Clínicas da UFBA, a concentração de fungos encontrada foi de 643 a 740 ufc-3, portanto muito mais alta do que na Bibliotheca Gonçalo Moniz. É importante considerar que durante a coleta das amostras de ar dentro da Bibliotheca Gonçalo Moniz, perto da entrada de tubo de captação de ar, não havia manipulação do acervo nem pessoas circulando no ambiente. Em situação adversa, provavelmente, o valor de ufc-3 seria aumentado.

Klucsar Neto e Siqueira (1998) consideram que, de acordo com a microflora existente nos ambientes interiores, a concentração de fungos deve ser qualitativamente similar e quantitativamente superior à existente no ambiente externo. Entretanto, com a presença confirmada de uma ou mais espécies de fungos típicos de interiores, ocorre um aumento significativo de fungos de uma amostra em ambiente interno e não presentes de forma similar em amostras exteriores, o que evidencia a existência de um amplificador (fonte poluente) de fungos no ambiente interior. $O$ rápido crescimento de fungos agressivos muitas vezes resulta em subestimação na avaliação, tanto da diversidade, como da abundância das populações fúngicas amostradas. (YANG; HEINSOHN, 2007)

Os resultados de ufc-3 de fungos encontrados dentro da Bibliotheca, perto da entrada do tubo de captação de ar, foram maiores (244 ufc-3) do que os encontrados fora, ao ar livre, próximo à saída do reator desligado $(117,0$ ufc-3). Essa diferença se deve principalmente ao fato de o ambiente da biblioteca oferecer algumas condições favoráveis ao surgimento de fungos, como muitas peças do acervo raramente manuseadas, local fechado e com pouca iluminação, umidade não controlada e baixa circulação de ar.

\section{CONCLUSÃO}

O presente estudo avaliou a possibilidade do uso do sistema de neblina ativada para redução de fungos na Bibliotheca Gonçalo Moniz, da Faculdade de Medicina da Bahia, da Universidade Federal da Bahia. O valor de $u f c / \mathrm{m}^{3}$ na biblioteca está mais baixo do que o referencial ANVISA de qualidade do ar interior, em ambientes climatizados artificialmente de uso público e coletivo. A utilização do sistema de neblina ativada apresentou uma expressiva diminuição dos fungos no ar da biblioteca, com redução de 95,7\%. O sistema de neblina ativada mostrou-se efetivo na redução de fungos em ambientes internos de biblioteca.

No entanto, considerando que, devido a problemas operacionais, a pesquisa limitou-se a uma biblioteca - ainda que suas características tenham sido adequadas a este estudo -, fazse necessário desenvolver estudos experimentais similares em outras bibliotecas, onde se inclua uma análise mais ampla do ambiente físico, isto é, levando em consideração não só a existência de fungos, mas de bactérias, além de variáveis como higienização, umidade e temperatura.

Perspectivas em Gestão \& Conhecimento, João Pessoa, v. 6, n. 2, p. 36-52, jul./dez. 2016. 


\section{REFERÊNCIAS}

ALVES, E. E. M. Uso de neblina ativada para redução das emissões e bioaerossois em um aterro sanitário. 2009. 66 f. Dissertação (Mestrado em Saúde, Ambiente e Trabalho) Faculdade de Medicina da Bahia, Universidade Federal da Bahia, Salvador.

AGÊNCIA NACIONAL DE VIGILÂNCIA SANITÁRIA. Resolução ANVISA-RE no 9 de 16 de janeiro de 2003. Orientação técnica elaborada por grupo técnico assessor sobre padrões referenciais de qualidade do ar Interior, em ambientes climatizados artificialmente de uso público e coletivo. Brasília, DF, 2003.

BORSATO, D.; GALÃO, O. F.; MOREIRA, I. Detergentes naturais e sintéticos: um guia prático. Londrina: Eduel, 1999.

BRICKUS, L. S. R.; AQUINO NETO F. R. A qualidade do ar de interiores e a química. Química Nova, Rio de Janeiro, v. 22, n. 1, p. 56-74, 1999.

BRUCE, N.; PEREZ-PADILLA, R.; ALBALAK, R. Indoor air pollution in developing countries: a major environmental and public health challenge. Bulletin of the World Health Organization, Geneva, v. 78, n. 9, p. $1078-1092,2000$.

CASSARES, Norma Cianflone. Como fazer conservação preventiva em arquivos e bibliotecas. São Paulo: Arquivo do Estado; Imprensa Oficial, 2000. (Projeto Como Fazer, v. 5). Com a colaboração de Cláudia Moi.

CENTERS FOR DISEASE CONTROL AND PREVENTION (USA). Preventing occupational respiratory disease from exposures causes by dampness in office buildings, schools, and other nonindustrial buildings. Atlanta, GA, 2013. (NIOSH Alert. Publication no. 2013-102). Disponível em: http://www.cdc.gov/niosh/docs/2013-102/pdfs/2013-102.pdf. Acesso em: 3 abr. 2014.

GIODA, A. Poluição atmosférica e de interiores: influência mútua e seus reflexos na saúde. 2003212 f. Tese (Doutorado Química Orgânica) - Universidade Federal do Rio de Janeiro, Rio de Janeiro.

GIODA, A.; AQUINO NETO F. R. Considerações sobre estudos de ambientes industriais e não industriais no Brasil: uma abordagem comparativa. Cadernos de Saúde Pública, Rio de Janeiro, v. 19, n. 5, p. 1389-1397, 2003.

HUNG, L. L.; MILLER, J.D.; DILLON, H.K. Field guide for determination of biological contaminants in enviromental samples. $2^{\text {nd }}$ ed. Virginia: American Industrial Hygiene Associations, 2005.

HERNANDEZ, R.T. Viabilidade da aplicação de neblina ativada na redução de bioaerossois em hospitais. 2011. 56 f. Dissertação (Mestrado em Saúde Ambiente e Trabalho) - Faculdade de Medicina da Bahia, Universidade Federal da Bahia, Salvador, 2011.

INDOOR ENVIRONMENT CENTER. Aerobiological engineering. Disponível em: http://www.engr.psu.edu/ae/iec/abe/index.asp. Acesso em: 10 jan. 2013.

ITO, L. X.; AGUIAR, M. L. Indoor air quality of libraries in São Paulo, Brazil. Indoor and Built Environment, São Paulo, v. 16, n. 2, p. 190-193, 2007. DOI: 10.1177/1420326X07076789.

LUBISCO, N. M. L. Relatório de pesquisa: bibliotecas universitárias, seus serviços e produtos: transposição de um modelo teórico de avaliação para um instrumento operacional. PontodeAcesso, Salvador, v. 8, n. 3, 2014. p. 1-61. Disponível em: 
http://www.portalseer.ufba.br/index.php/revistaici/article/view/12834. Acesso em: 02 set. 2014.

KLUCSAR NETO, F.; SIQUEIRA, L. F. G. Padrões referenciais para análise de resultados de qualidade microbiológica do ar em interiores visando a saúde pública no Brasil. Revista Brasileira de Saúde Ocupacional, São Paulo, v. 26, n. 97/98, p. 29-41, 2001. Disponível em: http://www.fundacentro.gov.br/arquivos/rbso/Artigos\%2097-98/V26\%20n97-98-03.pdf.

PEREIRA, S. S. et al. Controle da microbiota fúngica em uma biblioteca de uma universidade particular e seu impacto na saúde ocupacional. In: ENCONTRO LATINO DE INICIAÇÃO CIENTÍFICA, 14., e ENCONTRO LATINO AMERICANO DE PÓS-GRADUAÇÃO, 10., Vale do Paraíba, 2010. Universidade do Vale do Paraíba. Anais eletrônicos... Disponível em: http://www.inicepg.univap.br/cd/INIC 2010/anais/arquivos/0383 0320 01.pdf. Acesso em: 05 maio 2014.

QUADRO, M. E. Qualidade do ar em ambientes internos hospitalares: parâmetros físicos químicos e microbiológicos. 2008. 134 f. Dissertação (Mestrado em Engenharia Ambiental) Universidade Federal de Santa Catarina, Florianópolis.

RIBEIRO, A. L. P. de C. [Aspersor: foto tirada no ambiente da pesquisa]. Salvador: 2014.

SCHIRMER, W. N. et al. A poluição do ar em ambientes internos e a síndrome dos edifícios doentes. Ciência \& Saúde Coletiva, Rio de Janeiro, v. 16, n. 8, ago. 2011. Disponível em: http://www.scielo.br/scielo.php?pid=S1413-81232011000900026\&script=sci arttex. Acesso em: 02 set. 2014.

STRAUSZ, M. C. Análise de um acidente fúngico em biblioteca: um caso de síndrome do edifício doente. 2001. Dissertação (Mestrado) - Escola Nacional de Saúde Pública, Rio de Janeiro.

TAVARES, T. M.; ALVES, Eagles M.; ARCINIEGAS, Carolina L. W. Uso de neblina ativada para redução das emissões de bioaerossóis em um aterro sanitário. In: FERNANDES, R. C. P; LIMA, M. A. G.; ARAÚJO, T. M. Tópicos em saúde, ambiente e trabalho: um olhar ampliado. Salvador: Edufba, 2014. cap. 12.

WANG, S.; ANG H.M.; TADE, M. Volatile organic compounds in indoor environment and photocatalytic oxidation: state of the art. Environment International, v. 33, p. 694-705, Perth, 2007. Disponível em: http://www.ncbi.nlm.nih.gov/pubmed/17376530. Acesso em: 02 set. 2014.

YANG, C.S.; HEINSOHN, P.A. Sampling and analysis of indoor microorganisms. New Jersey: Wiley Interscience, 2007.

Artigo recebido em 17/12/2015 e aceito para publicação em 17/05/2016 